\title{
Studies on the Distribution Characteristics of the Cloud-to-Ground Lightning and Its Disasters Prevention in Xinjiang, China in 2017
}

\author{
Wenjun Ye1, Yanhui Wang1,2*, Yong Qian'1, Xiaolu Huang1, Yang Jiao', Zhongquan Liu1 \\ ${ }^{1}$ Meteorological Disaster Prevention Technology Center of Xinjiang Uygur Autonomous Region, Urumqi, China \\ ${ }^{2}$ Institute of Desert Meteorology, China Meteorological Administration, Urumqi, China \\ Email: *wyhwyc2085@sina.com
}

How to cite this paper: Ye, W. J., Wang, Y. H., Qian, Y., Huang, X.L., Jiao, Y., \& Liu, Z. Q. (2019). Studies on the Distribution Characteristics of the Cloud-to-Ground Lightning and Its Disasters Prevention in Xinjiang, China in 2017. Journal of Geoscience and Environment Protection, 7, 210-219.

https://doi.org/10.4236/gep.2019.711015

Received: October 11, 2019

Accepted: November 25, 2019

Published: November 28, 2019

Copyright $\odot 2019$ by author(s) and Scientific Research Publishing Inc. This work is licensed under the Creative Commons Attribution International License (CC BY 4.0).

http://creativecommons.org/licenses/by/4.0/

\begin{abstract}
Xinjiang, China is affected by geographical terrain and other factors, and is prone to lightning disasters. In order to effectively carry out lightning protection and disaster reduction work and improve defense capabilities, based on the data of lightning location monitoring in Xinjiang in 2017 and the statistics reports of the lightning disasters from 2015 to 2017, the characteristics of the cloud-to-ground (CG) lightning activities and disasters in Xinjiang were statistically analyzed. The results show that the CG lightning in Xinjiang is mainly the negative one, accounting for $79.7 \%$ of the total lightning. In 2017, the distribution of positive, negative and total the CG lightning months mainly focuses on June to August, and the main occurrence period is from 14 to 23 hours. The intensity of total the CG lightning and negative the CG lightning mainly distributes from 20 to $40 \mathrm{kA}$, and the peak value appears in $30 \mathrm{kA}$. The CG lightning intensity is mainly distributed in $30-70 \mathrm{kA}$. The distribution of the CG lightning density in Xinjiang is larger in the north than in the south and larger in the west than in the east. Lightning disasters mainly occur from May to August, accounting for 93.2 percent of the total, with the largest number in June. From 2005 to 2017, 44.6\% of lightning accidents occurred in farming and pastoral areas, followed by civil electronic equipment damage. In addition, electrical equipment, buildings and factory equipment are damaged by lightning strikes to varying degrees.
\end{abstract}

\section{Keywords}

Cloud-to-Ground Lightning, Lightning Density, Lightning Intensity, Lightning Disasters, Xinjiang of China 


\section{Introduction}

Lightning is an extremely long-distance discharge process in the atmosphere, usually accompanied by a strong convective weather process. It is a common natural phenomenon. According to satellite observations of global lightning, it is estimated that there are about 46 lightning strikes per second in the world. China has more than 70 lightning strikes per minute (Ma et al., 2008). Because of its strong current, hot high temperature, strong electromagnetic radiation and violent electromagnetic waves (Cui et al., 2014), lightning can cause tremendous damage in an instant, posing a huge threat to human and property safety.

Xinjiang is vast and deeply inland in the northwest of China, with complex geographical conditions and large terrain. The mountains and basins are surrounded by basins and mountains (Wen \& Shi, 2006; Zhang \& Zhang, 2006). Due to geographical terrain and other factors, it is most likely to occur strongly from summer afternoon to evening. The convective weather process is accompanied by lightning activity. Moreover, Xinjiang is rich in mineral resources and has many energy facilities. Once a lightning strike occurs, it will cause huge economic losses and social impact. In recent years, many experts in China have conducted a lot of research on the law of lightning activity and the temporal and spatial distribution characteristics of lightning disasters. Liu et al. (2018a, 2018b) and Yang et al. (2018) analyzed the characteristics of lightning flashover and the distribution characteristics of lightning disasters in Kunming and the province based on years of lightning monitoring and lightning disaster compilation data in Yunnan Province. Zeng et al. (2017), Zhang et al. (2018) and Wang (2011) used the lightning disasters of Shenzhen, Jiangsu and Hebei provinces for several years to analyze the time, region and industry distribution characteristics of the thunderstorms. Huo (2013), Liu et al. (2016), Wang et al. (2014, 2019), Wang \& Maimaitiiming (2018) used the thunderstorm day and ground flash data in Xinjiang to study the temporal and spatial variation of thunderstorm climate characteristics and lightning and its intensity.

A large number of studies have shown that domestic provinces have carried out analysis of thunderstorm days, lightning and their distribution characteristics, but the research on the characteristics of lightning and its disasters in Xinjiang is relatively lacking. This paper mainly uses Xinjiang lightning monitoring in 2017 and the statistical report of lightning disasters in 2005-2017 to comprehensively analyze the temporal, spatial, intensity and thunderstorm characteristics of Xinjiang lightning activities, which is conducive to understanding and mastering the local lightning activity law. The research on Xinjiang lightning early warning forecast provides basic parameters and provides a scientific theoretical basis for lightning protection and disaster reduction work in Xinjiang. It is of great significance to effectively carry out lightning protection and disaster reduction work and improve the actual defense capability against lightning disasters. 


\section{Data and Methods}

\subsection{Data Sources}

The data used in this paper was obtained by the Active Divectory Topology Diagrammer (ADTD) of Xinjiang, using the lightning at 00:00 from January 1, 2017 (Beijing time BT, the same below) to December 31, 2017. The location monitoring and the statistical report of the lightning disasters in 2005-2017 analyzed the distribution characteristics and laws of lightning and its disasters in Xinjiang.

\subsection{Data Processing Methods}

In this paper, the time, latitude and longitude and intensity of lightning in the original data of lightning location are extracted, and the mathematical statistics method is used for analysis. First, the meaningless data outside Xinjiang is removed. Secondly, the initial day of artificial observation of thunderstorms in Xinjiang is April, and the termination date is October. Therefore, the data after October and before October are removed. Thirdly, the low-frequency probe of the lightning locator may determine the small-scale cloud glitch as lightning, and eliminate the interference data with the current intensity in the range of -2 $2 \mathrm{kA}$ (Li et al., 2014). In addition, the above-mentioned $300 \mathrm{kA}$ or more is considered to be larger than the error (Bao et al., 2009). The data is finally classified into a lightning strike in the interval of 0.5 seconds and within $10 \mathrm{~km}$ between the front and rear time intervals (Yang et al., 2014), and the information retained for the first time is used as the statistical analysis of the lightning (Wang \& Maimaitiiming, 2018).

\section{Results and Analysis}

\subsection{Abbreviations and Acronyms}

According to the monitoring data of Xinjiang lightning real-time positioning system, there were 43,606 lightnings and 34,774 negative flashes in 2017, accounting for $79.7 \%$ of the total. Zhengde 8832 times, accounting for $20.3 \%$ of the total; mainly distributed in the north-north region (see Figure 1); summer (June-August) is the high season of lightning, accounting for $77.0 \%$ of the total; from 14:00 to 22:00. The high-risk period of lightning accounts for $62.0 \%$ of the total.

The distribution of positive, negative and total flash months in 2017 was mainly concentrated in June-August, which were $6516,27,059$ and 33,575 respectively, which in turn accounted for 15.0, 62.1 and $77.0 \%$ of the total. Among them, the negative flash and total flash reached the highest in August (9956, 12,010 ), accounting for $22.8 \%$ and $27.5 \%$ of the total, respectively; while Zhengxue peaked in June (2511), accounting for 5.8 of the total year. \%. The total flash occurred less in April; the least in October, only $0.07 \%$ of the total for the whole year, and almost no lightning occurred in March of the following year. In 2017, except for April and August, the number of lightnings was less than the average number of lightnings in the past three years (see Figure 2). 


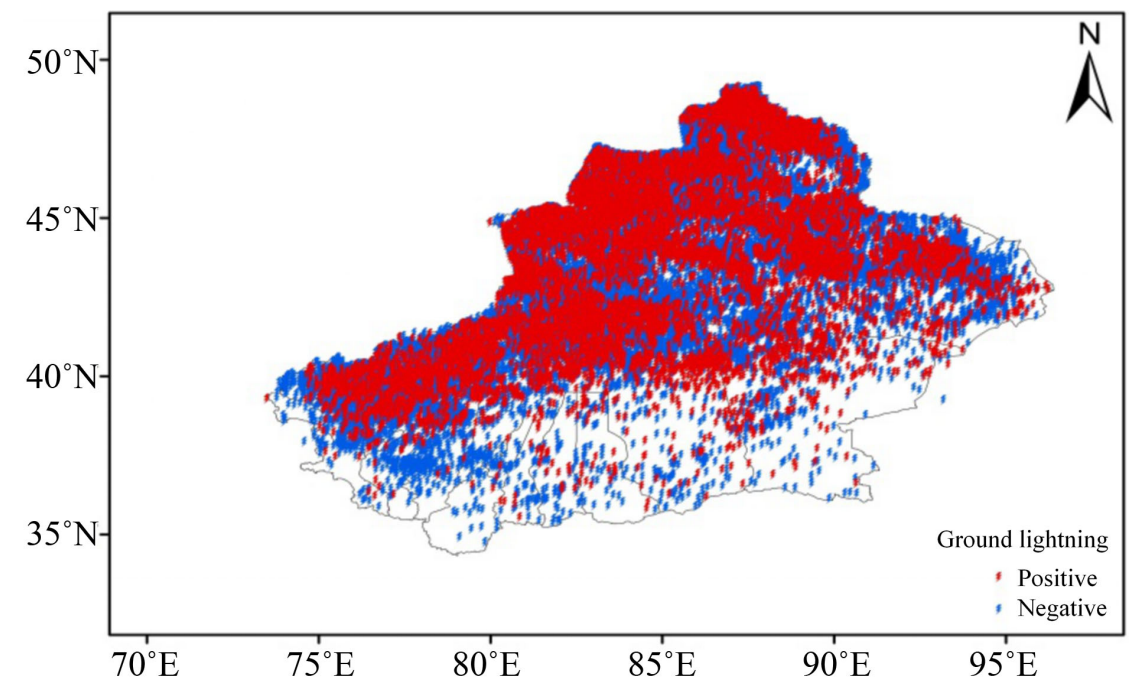

Figure 1. Xinjiang lightning distribution in 2017.

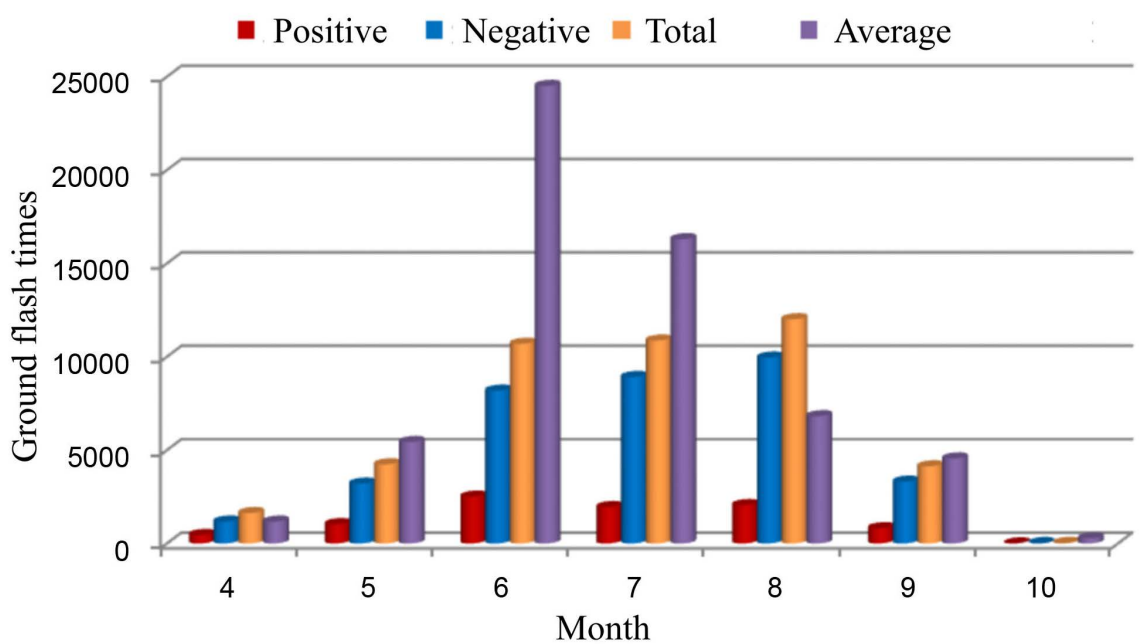

Figure 2. Xinjiang lightning month distribution in 2017.

The main occurrence periods of positive, negative and total flash in 2017 were 14 to 23 , which were $5923,23,056$ and 28,979, respectively, accounting for 13.6, 52.9 and $66.5 \%$ of the total. Both the total flash and the negative flash occurred at the lowest number of times at $09-12$, and reached the peak of the day at 17:00 and 19:00 (3789, 3103 times), while the positive flash was at the low value of the number of lightning occurrences at 6 - 11. District, and reached its peak at 1700 hours. The number of lightning strikes in 2017, except for the hours of 05 to 09 and 11:00, was lower than the average number of lightnings in the past three years. It can be seen from the above that Xinjiang is generally prone to strong convective weather after 14:00 (as shown in Figure 3).

In 2017, the lightning density area was mainly concentrated in the areas of Altay, Aksu, Kizilsu Kirghiz Autonomous Prefecture and Tacheng in the north-north of our district. The total lightning density was less than 0.261 times $/ \mathrm{km}^{2} \cdot \mathrm{a}$. The higher density areas are mainly distributed in Karamay, Wusu, Shawan, Changji, 


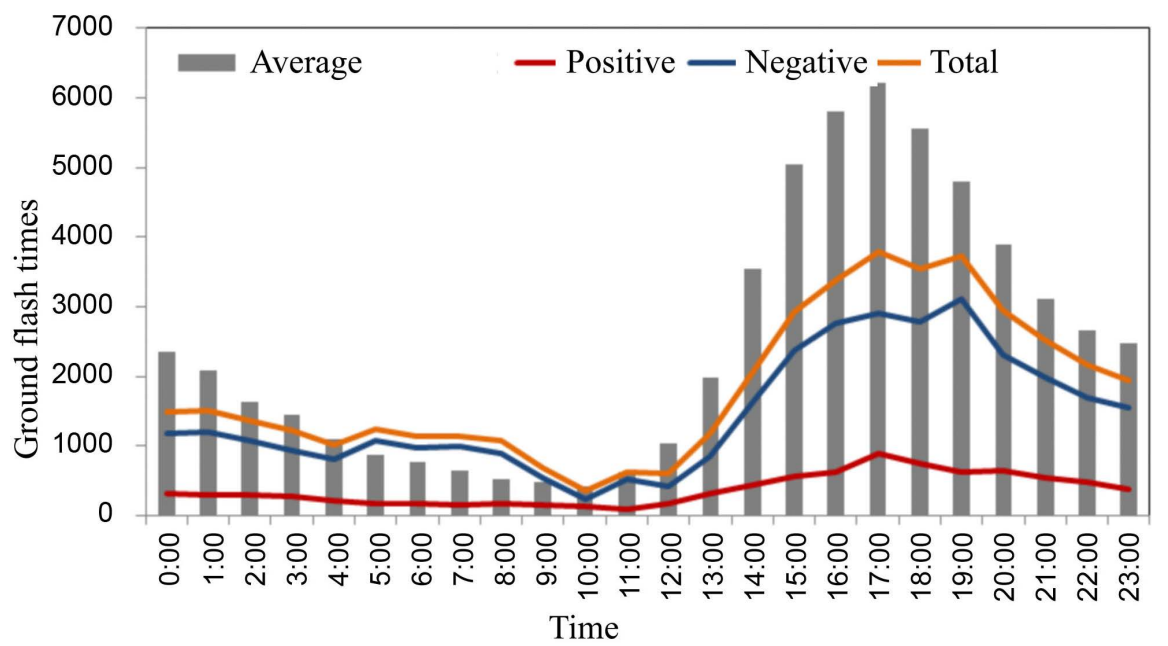

Figure 3. Xinjiang lightning time distribution in 2017.

Hutubi and Manas. The density of lightning in the Hetian and Desert Gobi areas of southern Xinjiang is the smallest. The lightning density distribution in Xinjiang shows that the northern Xinjiang is larger than the southern Xinjiang, and the western region is larger than the eastern region. In 2017, the total flash and negative flash intensity were mainly distributed at $20-40 \mathrm{kA}$, accounting for $65.6 \%$ and $74.8 \%$ of the total, respectively, and the peaks were all at $30 \mathrm{kA}$; the positive flash intensity was mainly distributed at $30-70 \mathrm{kA}$, accounting for $64.6 \%$ of the total number of positive flashes; The total flash intensity is $99 \%$ less than $150 \mathrm{kA}$ and is significantly less frequent than in the last 3 years (Figure 4).

In 2017, the average intensity of positive, negative and total flash months fluctuated little from May to August, and the overall trend showed a slow decline. From the average amplitude of lightning current intensity in September, it gradually increased to the maximum in October, followed by 67.2, 59.6, 61.4 kA. Among them, the average lightning current intensity of positive flash from April to September is about twice that of negative flash. In 2017, the average lightning intensity was weaker than the average of lightning intensity in the past three years in April and August to September, and the average was stronger in the past three years from May to July and October (Figure 5).

The lower and upper bases of the box in Figure 6 represent the magnitude of the lightning intensity of $25 \%$ of the total sample size of the month, respectively, and the endpoints of the two end whiskers (the extended vertical line) represent the $10 \%$ of the lightning intensity of the total number of samples per month. $50 \%$ of the total number of lightnings occurred between 25 and $50 \mathrm{kA}$ in April-September. The amplitude of the lightning current intensity occupied in October is longer; in the April to October, it accounts for $10 \%$ of the total monthly sample, and the lightning intensity is greater than $7 \mathrm{kA}$. In April, 80\% of the total number of lightnings occurred in the amplitude span of 7 to $100 \mathrm{kA}$. As the month changed, the amplitude span gradually contracted, and gradually expanded in September and October. 
W. J. Ye et al.

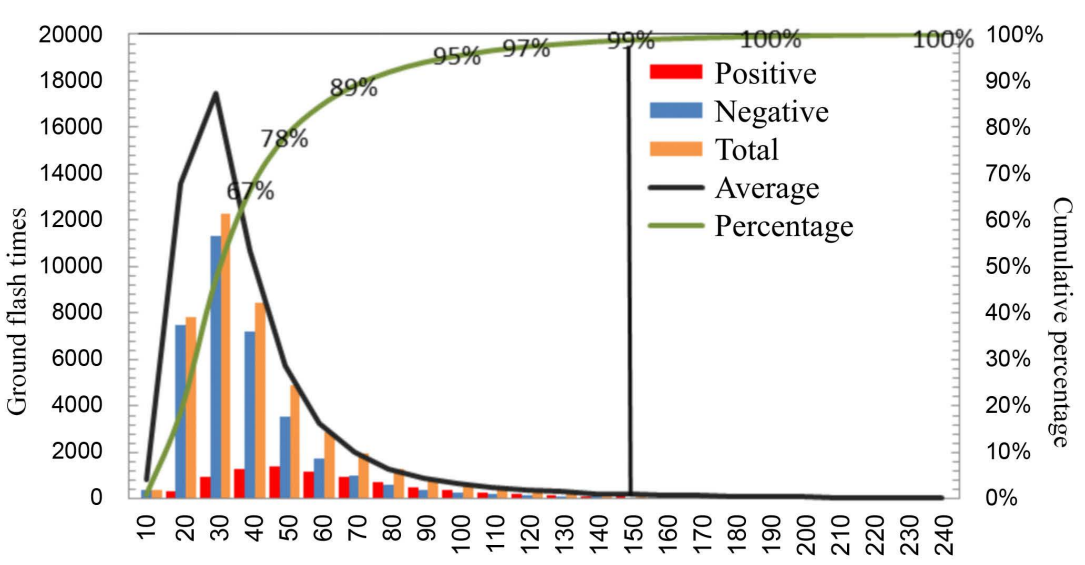

Lightning current intensity/kA

Figure 4. Xinjiang lightning intensity distribution in 2017.

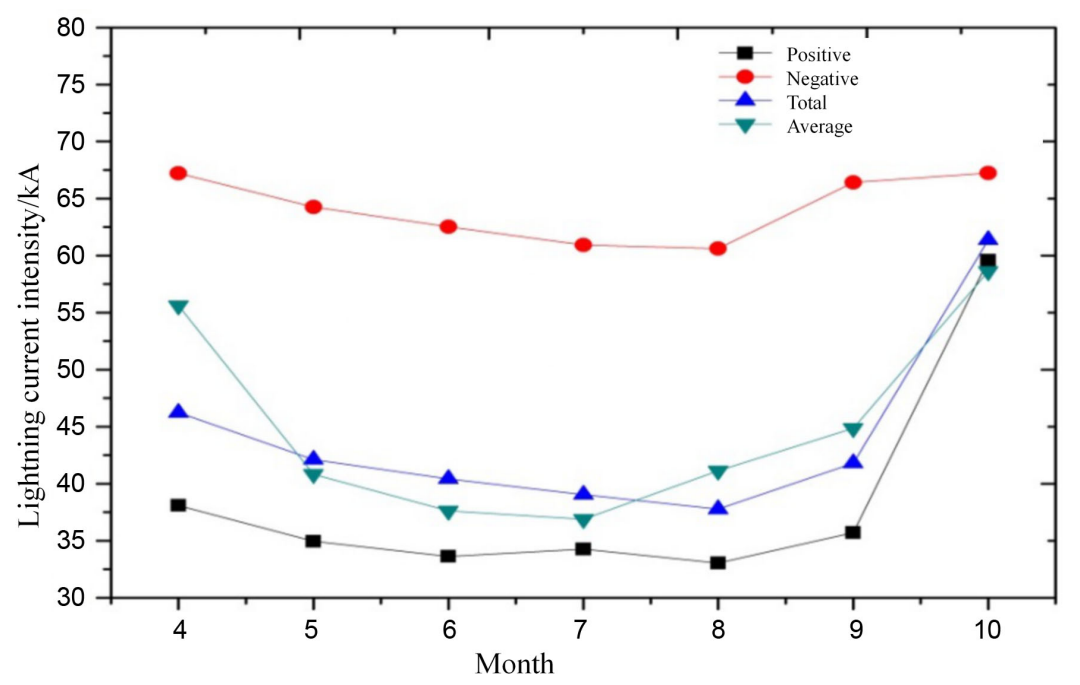

Figure 5. Average intensity distribution of Xinjiang lightning month in 2017.

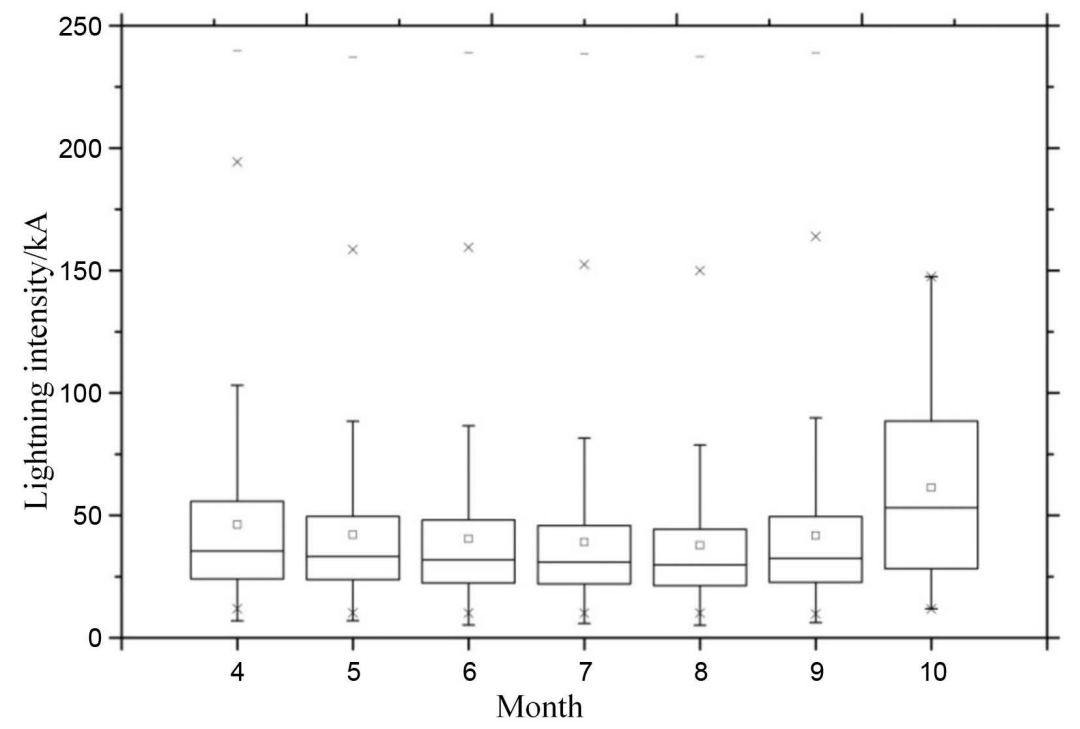

Figure 6. Monthly distribution of lightning intensity in Xinjiang in 2017. 


\subsection{Distribution Characteristics of Lightning Disasters}

In 2017, there was no statistical report on lightning disasters in Xinjiang. However, in the law enforcement inspection of lightning safety supervision, it was found that there were still lightning disasters in Xinjiang, and even there were lightning disasters with losses exceeding 600,000 Yuan. For example, at 16:00 on June 30, 2017, the pivotal simple substation of a city's agricultural development zone was struck by lightning, and the working equipment of a company's work area was damaged by lightning strikes around 15:18 on August 1st, 2017. And in the early morning of September 8th, 2017, the industrial sewage pipe of a company's natural gas processing station was struck by lightning. According to the statistics of thunderstorm data in the past 13 years in Xinjiang (Figure 7), the thunderstorms mainly occurred from May to August, accounting for $93.2 \%$ of the total. The most is in June, 63 times, followed by July.

The $44.6 \%$ of the lightning disasters occurred in the agricultural and pastoral areas in 2005-2017, causing some farmers and herdsmen to suffer casualties. The main reason is the imperfect lightning protection measures in the agricultural and pastoral areas, the lack of knowledge on lightning protection and disaster reduction, and the awareness of mines and herdsmen It is not strong; secondly, the damage of civilian electronic equipment accounts for $34.5 \%$ of the total number of lightning disasters, mainly because the installation of lightning protection devices for electronic equipment in some towns and cities does not meet the standards. In addition, electrical equipment, buildings, and factory equipment are damaged to varying degrees due to lightning strikes (as shown in Figure 8).

\section{Conclusion and Recommendation}

The lightning activities in Xinjiang are mainly distributed in the north-north region. A total of 43,606 lightnings occurred, with 8832 flashes and negative flashes

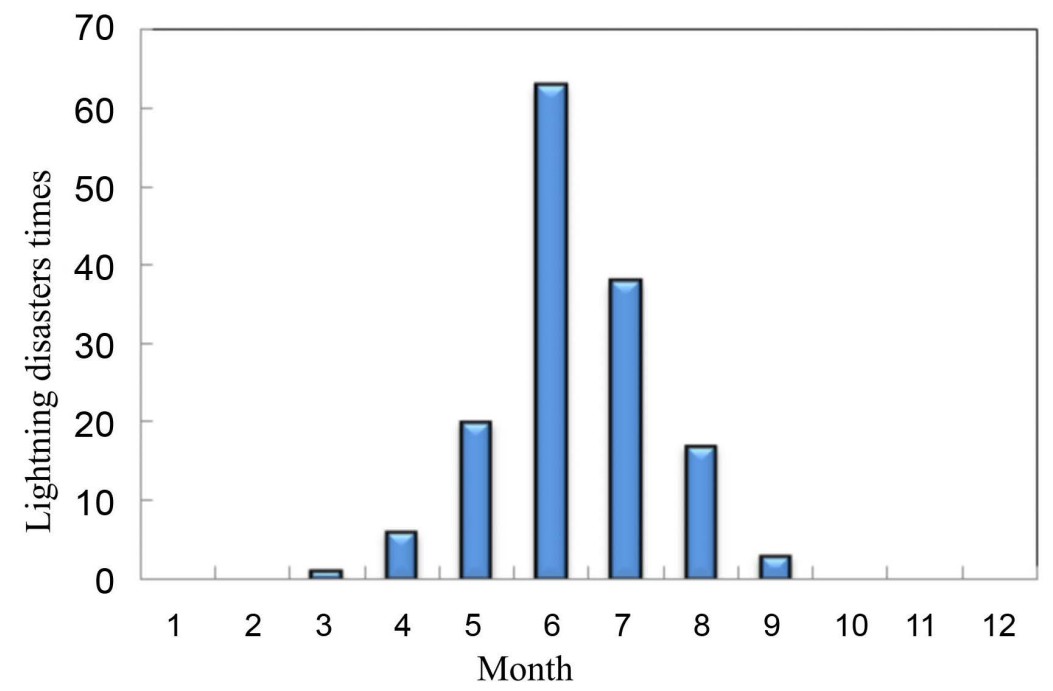

Figure 7. Monthly distribution of lightning disasters in 2005-2017. 


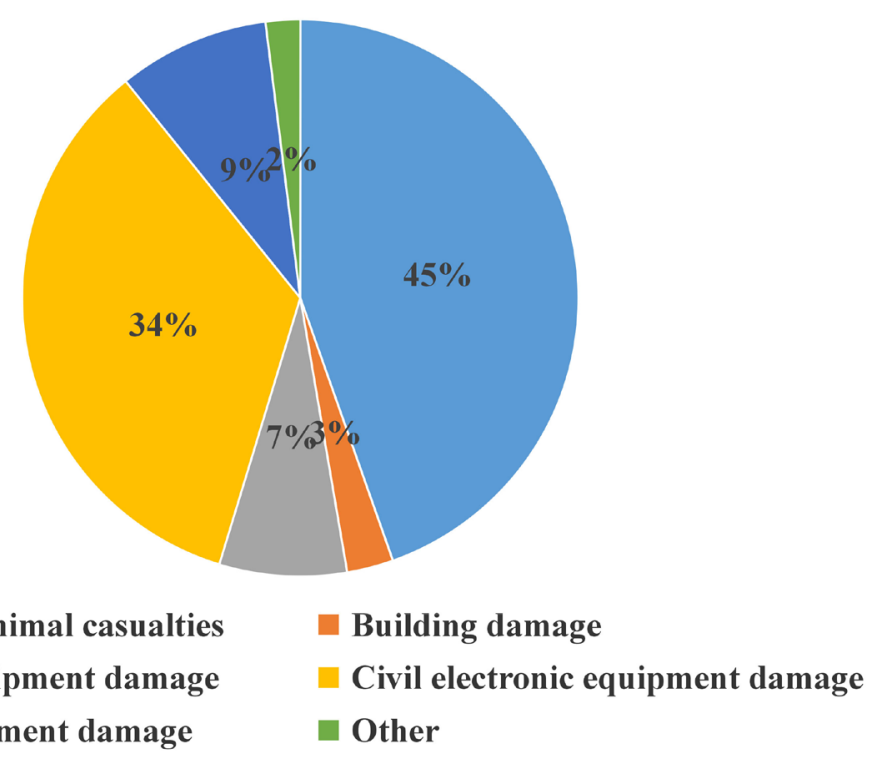

Figure 8. Distribution of lightning disasters in 2005-2017.

accounting for $79.7 \%$ of the total. However, the average intensity of positive flash is about twice that of negative flash. Although the number of positive flashes is small, its intensity is large. Summer (June-August) is the high season of lightning, accounting for $77.0 \%$ of the total; At 2 o'clock, the high-incidence period of lightning is $62.0 \%$ of the total; the total flash intensity is mainly distributed at $20-40 \mathrm{kA}$, accounting for $65.6 \%$ of the total. In addition, the lightning month is distributed into a single peak type, mainly concentrated in June-August, followed by May and September, and the least in April and October; while the average intensity of lightning is the strongest in October, followed by April, May and September, the weakest in June-August. It can be seen that although the lightning in Xinjiang mainly occurs in summer, spring and fall. The lightning intensity is weak in summer and strong in spring and fall.

According to the statistics of lightning disaster statistics in Xinjiang in the past 13 years, the lightning disaster mainly occurred in May-August, accounting for 93.2\% of the total, of which the most was in June. In the 2005-2017 lightning disaster, $44.6 \%$ of accidents occurred in agricultural and pastoral areas, followed by damage to civilian electronic equipment. In addition, electrical equipment, buildings, and factory equipment are damaged to varying degrees due to lightning strikes.

In response to lightning disaster prevention, we propose the following suggestions: First, governments at all levels and lightning protection authorities should attach great importance to lightning disaster prevention work, especially lightning and lightning disaster prevention in agricultural and pastoral areas, strengthen the publicity of lightning protection laws and regulations and popular science knowledge, and enhance the people's and herdsmen's awareness of lightning protection and self-rescue ability to avoid or mitigate the damage caused by lightning disasters. 
Second, meteorological stations at all levels should make full use of monitoring data such as lightning monitoring network and atmospheric electric field instrument to improve the prediction and warning level of lightning, and timely release lightning warning information. The competent meteorological agencies at all levels should report the lightning disaster investigations and statistics to the lightning disasters that have occurred. All enterprises and institutions are the main body responsible for lightning protection safety. After a lightning disaster, they should report to the local meteorological authority in time, and cooperate with the disaster investigation and collection to continuously summarize the lightning disaster prevention experience and improve the defense measures.

Third, all levels of meteorological authorities and departments responsible for lightning safety supervision should strengthen the lightning protection safety supervision and law enforcement inspection in accordance with relevant state laws and regulations, and all enterprises and institutions should strengthen their own lightning protection safety facilities and systems. Do an annual inspection of lightning protection safety to ensure lightning protection in Xinjiang.

\section{Acknowledgements}

This research was funded by the Xinjiang Meteorological Bureau Scientific Research Project (MS201808) and the China Desert Meteorological Science Research Fund (Sqj2018013).

\section{Conflicts of Interest}

The authors declare no conflicts of interest regarding the publication of this paper.

\section{References}

Bao, B. S., Yang, A. L., Liu, X. L. et al. (2009). Discussion on the Evidence of Lightning Current Amplitude Monitored by Lightning Location System. Hangzhou: The 26th Annual Meeting of the Chinese Meteorological Society.

Cui, H. H., Wu, M. H., \& Zhai, Y. (2014). Research on Lightning Monitoring and Forecasting and Disaster Reduction Countermeasures in Hebei Province. China Science and Technology Achievements, 22, 74-75.

Huo, G. Y. (2013). Temporal and Spatial Distribution and Variation Characteristics of Thunderstorms in Xinjiang from 1961 to 2012. Journal of Glaciology and Geocryology, 35, 1156-1164.

Li, J. Q., Pei, J., Wang, P. et al. (2014). Study on the Range of Small Amplitude Ground Flash in Quality Control of Lightning Location Data. High Voltage Technology, 40, 727-731.

Liu, P. Y., Zhang, T. F., \& Zhou, Q. Q. (2018a). Analysis of Disaster-Causing Factors and Vulnerability Risk Zoning in Kunming from 2006 to 2016. Meteorological Science, 38, 824-831.

Liu, P. Y., Zhou, Q. Q., Hu, Y. et al. (2018b). Changes in Cloud-to-Light Flashover Activity and Temporal and Spatial Distribution Characteristics of Lightning Disasters in Yunnan Province in the Past 12 Years. Meteorological Research and Application, 39, 
86-91.

Liu, Z. H., Wang, S. G., Shang, K. Z. et al. (2016). Study on the Short-Term Forecast of Thunderstorms in the Southern Tianshan Mountains. Journal of Desert and Oasis, 10, 43-49.

Ma, M., Zhang, Y. J., Meng, Q. et al. (2008). Lightning Disasters and Their Defense in China. China Emergency Management, 12, 55-57.

Wang, H., Zhang, Y. J., Chen, J. G. et al. (2014). Analysis of Thunderstorm Characteristics Based on Lightning Location Monitoring Data. Journal of Desert and Oasis, 8, 66-69.

Wang, J. H. (2011). Research on Distribution Characteristics and Risk Zoning of Lightning Disasters in Hebei Province (pp. 1-57). Nanjing: Nanjing University of Information Science and Technology.

Wang, Y. H., \& Maimaitiiming, M. (2018). Analysis of the Characteristics of Xinjiang Ground Flash Activity in 2013-2016. Desert and Oasis Meteorology, 12, 43-49.

Wang, Y. H., Zhang, J. T., He, Q. et al. (2019). Analysis of the Relationship between Thunderstorm Climate Characteristics and Earth Flash Density in Xinjiang. Journal of Chengdu University of Information Technology, 34, 180-185.

Wen, K. G., \& Shi, Y. G. (2006). China Meteorological Disaster Code: Xinjiang Volume (pp. 1-3). Beijing: China Meteorological Press.

Yang, X. L., Sun, J. H., \& Li, W. L. (2014). An Analysis of Cloud-to-Ground Lightning in China during 2010-13. Weather \& Forecasting, 30, 1537-1550. https://doi.org/10.1175/WAF-D-14-00132.1

Yang, Z. K., Liu, P. Y., Hu, Y. et al. (2018). Distribution Characteristics of Lightning Activity in Yunnan Province and Its Impact on Rural Areas. China Agricultural Resources and Regionalization, 39, 262-267.

Zeng, Q. F., Xu, D. W., Jiang, W. et al. (2017). Analysis of Lightning Activity and Thunderstorm Characteristics in Shenzhen from 2013 to 2016. Guangdong Meteorology, 39, 36-39.

Zhang, W., Li, H., \& Bian, X. W. (2018). Statistical Analysis of Characteristics of Lightning Disasters in Zhejiang Province from 2007 to 2013. Meteorological and Environmental Sciences, 41, 139-143.

Zhang, X. W., \& Zhang J. B. (2006). Xinjiang Meteorological Manual (pp. 72-81). Beijing: China Meteorological Press. 